\title{
La expresión lingüística de los niños pequeños
}

\section{Claudine Dannequin}

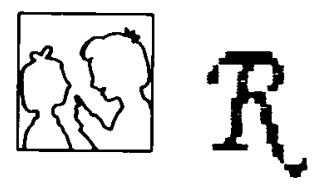

¿Por qué hablan o no bablan los niños de preescolar en la clase de conversación? ¿Por qué hablan mucho unos y otros poco, de una manera o de otra? ¿Por qué hablan menos y peor cuando se da clase de "hablar" que cuando están baciendo algo y la conversación tiene un objeto? Cómo analizar y evaluar el lenguaje? ¿Cómo ayudar al niño a mejorar su lenguaje apoyándose en sus "faltas" o errores? En este artículo, la autora aborda esos problemas y propone vías más eficaces para la educación del lenguaje oral en preescolar.

\section{AL LLEGAR A LA ESCUELA, EL NIÑO YA HABLA}

Mucho antes de llegar a la escuela infantil, el niño ya está incluido en una red de comunicación preverbal: las observaciones realizadas con niños de 10 meses a 2 años muestran que tienen capacidades sorprendentes; situados frente a objetos variados (cartones, perlas, etc.), saben no sólo explorar las diferentes posibilidades de juego que ofrecen esos objetos, sino que son igualmente capaces de inventar juegos de ficción entre dos o tres niños!.

Los primeros intercambios lingüísticos que tienen lugar en la familia y, en̂ particular, con la persona que se ocupa regularmente del niño ( uno de los padres u otra persona: nodriza, hermano mayor, etc.) se reorganizan muy pronto por los intercambios verbales que el niño puede mantener con otros adultos y sobre todo por las relaciones que establece en la guardería, y más tarde en preescolar, con los otros niños de la misma edad (el grupo de iguales).

"L'expression linguistique des jeunes enfants». Reproducido con autorización de la autora. (C) Traducción al castellano, CLEE, 1989 (Traducción de Cintia Rodríguez). 
La influencia del grupo de compañeros es muy importante a partir de los 4-5 años y una gran parte de los comportamientos lingüísticos verbales y no verbales se adquieren, en realidad, en contacto con los otros niños y no solamente gracias a las relaciones privilegiadas con el adulto: en las encuestas sociolingüísticas que abordan el sistema fonológico de las familias que viven en las grandes aglomeraciones urbanas en los Estados Unidos, William Labov ha comprobado que la forma de hablar de los niños y adolescentes que provienen de medios geográficos diferentes era muy parecida, mientras que la de sus padres conservaba los acentos específicos de sus lugares de origen. El tipo de niño que habitualmente encontramos en preescolar, en absoluto está desprovisto de lenguaje: posee una experiencia como sujeto hablante situado en una comunidad lingüística determinada. Algunos, sin embargo, parecen tener más dificultades que otros a la hora de expresarse, espontáneamente hablan menos, o su lenguaje es abundante pero parece confuso, no estructurado: ¿tienen esos niños «un retraso» lingüístico o bien habría que plantearse la cuestión en otros términos?

\section{CIRCUNSTANCIAS EN QUE SE TOMA LA PALABRA}

Sin descuidar las dificultades particulares que puede tener tal o cual niño, es preciso constatar que las dificultades lingǘsticas a los 4-5 años son de diferente tipo y que, según las circunstancias, el lenguaje es rudimentario o, al contrario, muy complejo: a los adultos les ocurre lo mismo. Qué le responderíamos a una persona que nos preguntara « $i$ Qué ve usted en esta foto?" sino "un + sustantivo» (es decir, enumerando los objetos o los personajes).

Sin embargo, cuando los pedagogos plantean la misma pregunta a los niños (sirviéndose de imágenes o de libros de historias, etc.), a menudo esperan más por parte de sus interlocutores: el niño que se limita a responder «un sustantivo» es rápidamente considerado como poco verbal; a quien da más detalles, al que le gusta "contar» una pequeña historia acerca del dibujo, a quien pregunta al adulto o manifiesta interés, a menudo se le aprecia: le gusta hablar, demuestra conocer la importancia del lenguaje, pues no se trataba solamente de reconocer unos animales $u$ objetos en una imagen, sino de otra cosa.

Desde hace algunos años, los lingüistas se preguntan acerca de las circunstancias en las que se producen los enunciados que estudian. Las observaciones en clase han permitido comprender mejor por qué ciertos ninos «no participan» en los ejercicios de lenguaje: la situación asimétrica en la que se desarrollan los momentos de producción lingüística (un adulto intenta "hacer hablar» a los niños, les plantea preguntas sobre acontecimientos a menudo conocidos por todos y el niño no ve siempre el interés de responder de manera exhaustiva a esas preguntas) es a veces interpretada por los alumnos como situaciones «engañosas» donde lo importante es decir lo menos posible.

Preguntas que pueden reafirmar a unos niños pueden resultarles turbadoras a otros y provocarán comportamientos lingúísticos muy diferentes: es más agradable hablar del papá cuando es médico o profesor que cuando es un obrero en paro; es más gratificante contar que acabamos de volver 
de vacaciones en la montaña que confesar que toda la familia se ha quedado encerrada viendo la televisión en una vivienda modesta de la periferia...

Sin embargo, otras observaciones lo demuestran, se puede llegar a reducir la distancia entre el adulto y el niño modificando la situación de comunicación. En un artículo muy conocido, el lingüista W. Labov cuenta cómo un niño negro de un getto americano al que maestros y psicólogos estaban de acuerdo en calificar de "poco inteligente y retrasado en el dominio del lenguaje» podía repentinamente dar muestras de capacidades lingüísticas importantes. Este niño, prácticamente mudo cuando se le preguntaba en el marco de la escuela, recobraba todas sus posibilidades cuando el intercambio lingüístico tenía lugar fuera de ella, en su barrio, en torno a un paquete de patatas fritas, con uno de sus amigos y un adulto negro que conocía bien la cultura del getto ${ }^{2}$.

Desde entonces, se han realizado muchas observaciones del mismo tipo; las actividades pedagógicas centradas en proyectos concebidos y gestionados por los propios niños confirman que los «momentos en que se habla», disociados de otras actividades y a menudo sin relación con la vida real del niño, no ayudan a los alumnos a progresar en el dominio de la comunicación, mientras que las discusiones que conllevan la fabricación de un objeto, la preparación de una fiesta o de un documento exigen de los niños esfuerzos de comunicación bastante más complejos que realizan con placer.

\section{DIFERENTES TIPOS DE DISCURSO}

Podemos, para convencernos, examinar dos secuencias grabadas en clase:

\section{Primera secuencia:}

Profesora.- ¿Cómo se llamaba el niño de la historia?

Un alumno.-Christophe.

Profesora.- ¿Quién puede decirme dónde encontró Christophe las flores que queria regalar?

Un alumno.-En el jardín.

Profesora.-En el jardín de su papá, muy bien. ¿Qué flores podemos encontrar en un jardin?

Un alumno.-Tulipanes.

Profesora.-Si, tulipanes. ¿Y qué más?

\section{Segunda secuencia:}

Los niños están preparando un espectáculo de marionetas; la profesora distribuye trapos, pinturas, marionetas. Los niñoś discuten libremente con ella y entre ellos. En un momento dado la profesora pregunta a Frédéric: "¿Y tú, para la bruja, qué marioneta vas a coger?". Frédéric le responde: "La marioneta.. la que... mmb la marioneta que Agnés ha roto el brazo". Un poco más tarde, cuando están confeccionando las máscaras, Pascal le dice a la profesora: "Sabes, mi manita no puede venir mmb, no puede venir mi bermanita poque tiene la gadgantalla garganta muy roja y amás 
bem... mi mamá eb hum hoy hum mañana ha llamado al médico y amás hem... mi manita lloraba bem tenia miedo, si."

En la primera secuencia, el diálogo entre el profesor y los alumnos se reduce en realidad a una especie de monólogo realizado por el adulto, puntualizado por preguntas a las que los alumnos deben responder en pocas palabras. Toda la organización del discurso, los puntos de referencia temporales, la jerarquización de los acontecimientos y su presentación están reservados a la exclusiva iniciativa del profesor; el niño no interviene más que cuando se le pregunta y las respuestas sólo aparecen para que el adulto verifique que la historia leída ha sido bien comprendida. ¿Cómo darse cuenta, en esas condiciones, si el niño tiene dificultades lingǘsticas? ¿Cómo animarle a expresarse y ayudarle, si fuera necesario, si nos limitamos a hacerle realizar una especie de «extraño" ejercicio consistente en la repetición periódica de frases "prototípicas" que deberá interiorizar para hablar correctamente? (ejemplo: «Y bien, ahora vamos a decir lo que Christophe ha ido a buscar: Christophe ha ido a buscar tulipanes en el jardín. Repetid!»).

En la segunda secuencia, al contrario, encontramos unos niños involucrados en las dificultades surgidas en una conversación real: sus enunciados son espontáneos y motivados por las necesidades de una comunicación precisa entre ellos y el adulto.

\section{¿HABLAN MAL LOS NIÑOS?}

¿Cómo analizar estos enunciados? ¿Qué nos enseñan acerca de los niños que los producen? ¿Cómo caracterizar el lenguaje de los niños en la escuela infantil? ¿Se trata de un sublenguaje, una elaboración incompleta, un reflejo aún inacabado del lenguaje de los adultos? ¿Las dudas, las expresiones que un oído adulto puede encontrar "raras", son "faltas" que deben ser rápidamente corregidas? ¿Cómo ayudar al niño a dominar mejor la comunicación apoyándose en lo que ya conoce, en toda la experiencia lingüistica que ha acumulado desde el nacimiento?

En los enunciados producidos por Frédéric y Pascal, ciertas expresiones deben atraer la atención del pedagogo: para hablar de la marioneta a la que Agnés había roto el brazo, Frédéric dice que quiere "la marioneta ... la que... mmb/la marioneta Agnés ha roto el brazo". Por qué se produce esta situación embarazosa? Hubiera sencillo para Frédéric decir «la marioneta con el brazo roto" o bien "la que tiene el brazo roto". Pero he aquí que en el cesto donde estaban las marionetas, dos de ellas habían tenido un brazo roto. ¿Cómo designarlas si no es especificando quién había cometido este acto?

Con valentía, Frédéric se lanza a una descripción que organiza lungüísticamente con dificultad: tiene que hablar a la vez de la marioneta y de una acción que ha sido realizada con ella; es bastante más difícil que describir el objeto indicando solamente el resultado de lo que ha pasado: «la marioneta ha tenido el brazo roto", "le han roto el brazo".

Los trabajos en psicolingüística muestran que la utilización completa de un sistema de pronombres relativos no se organiza antes de los 8-9 años (e incluso más tarde en ciertos casos difíciles). A 5-6 años, el niño domina muy bien el $q u e^{*}$, pero encuentra dificultades en otras casos (aunque en 
el discurso espontáneo y en situaciones precisas se observan utilizaciones adecuadas de que, a la que, en que... pero su empleo no es sistemático).

En el relato de Pascal, constatamos que las indicaciones temporales son dudosas: las desinencias de los verbos están en contradicción con el empleo de mañana donde se esperaba ayer. Por lo demás, el niño se da cuenta de las dificultades que tiene para expresar el tiempo, puesto que comienza por bo (hoy) y rectifica: mañana.

¿Debemos concluir que el lenguaje de esos niños es simplemente una imitación aún incompleta del de los adultos? Es preferible tomar esos enunciados como indice de la construcción de un sistema cada vez más complejo. En efecto, Frédéric, al escoger la vía más difícil, produce un enunciado menos "prototípico", menos conforme a la norma y a las expectativas del adulto, pero sus dudas nos indican que está adquiriendo parte del sistema del pronombre relativo: enunciados aparentemente mal construidos y confusos pueden ser erróneamente interpretados por el adulto como una regresión en relación a lo que el niño era capaz de producir unos meses antes; son sin embargo esos intentos titubeantes, donde el niño trata de dar cuenta de varios aspectos de la realidad, los que llevan la marca de la evolución de su sistema lingüístico.

De la misma forma, emplear mañana por ayer es evidentemente un error en relación a la gramática de los adultos. Pero Pascal manifiesta ya una gran capacidad para manejar las oposiciones temporales en las desinencias de los verbos: mi hermanita no puede venir porque tiene la garganta muy roja / mamá ba llamado el médico/ mi hermanita lloraba.

La utilización de los adverbios de tiempo, aunque no están empleados de manera totalmente adecuada (y el caso es muy frecuente hasta 6-7 años) son sin embargo un signo de que el niño llega a construir el relato tomando varios puntos de referencia temporales; la construcción del relato de Pascal no sigue únicamente la cronología de los acontecimientos, puesto que a la constatación de la ausencia de la hermanita (situada en el presente del enunciado) le sigue una descripción de acontecimientos que se han desarrollado anteriormente y cuyas consecuencias motivan el relato actual.

El niño construye, pues, su propio sistema, basándose en lo que ya domina (una parte del paradigma del relativo para Frédéric, cierta idea de la sucesión de los acontecimientos y de las posibilidades que ofrece la lengua para expresarlos en el caso de Pascal). Cada etapa no destruye la anterior, sino que la reestructura y la completa. El adulto puede, cuando lo juzga necesario, intentar hacer sentir al niño que ciertos de sus enunciados son equívocos o confusos". "¿Cuándo vino el médico a ver a tu hermanita?". Si este tipo de preguntas perturba al niño; si cuando se le pide especificar si la visita tuvo lugar ayer/boy o mañana, el niño se queda pensando, podemos sugerirle que hay una diferencia entre algo que ocurrió ayer o que tendrá lugar mañana. Pero pretender forzar las etapas no sirve para nada si el niño no está ya listo para encontrar por sí mismo la solución: tan sólo en ese momento la ayuda del adulto le será útil; una ayuda demasiado precipitada corre el riesgo de dejarlo indiferente o incluso de molestarle.

Muy a menudo, los adultos están atentos a los «defectos» del lenguaje infantil y localizan formas «no normalizadas" que pasarían inadvertidas en los enunciados de otros adultos o en su propio lenguaje: toda producción 
oral se aleja de lo escrito y ese fenómeno aparece con toda claridad cuando «transcribimos» de lo oral.

Las marcas específicas de lo oral son entonces interpretadas como «errores» o "retrasos» en la adquisición. Las rupturas de construcción, las dudas (mmb...entonces...y...) sirven para puntualizar el discurso oral, le dan coherencia, le permiten al sujeto avanzar en sus explicaciones. A muchos enseñantes les gustaría que el niño produjera frases muy asépticas, sin fallos, como las repeticiones pleonásticas del sujeto (mi hermanita ella, mi mamá ella...), los heu, $m m b, y$, entonces, etc.

Pero querer obligar al niño a hacer "frasecitas correctas" del estilo: "Ayer mamá llamó al médico. Mi hermanita lloraba, pues tenía miedo", es obligarle a hablar como se escribe; es situarle en una situación falsa, puesto que se le imponen limitaciones que no están justificadas por las condiciones de producción del discurso en el momento en que tiene lugar. En vez de ayudar al niño, eso no sirve más que para oscurecerle la distinción, sin embargo fundamental, entre el lenguaje escrito y el oral.

Otros aspectos de los enunciados de Frédéric y Pascal muestran igualmente variedades del francés y no son "faltas": / $\varepsilon /$ o /al/ en vez de elle, $/ i /$ en vez de $i l \%$. Esto es conocido desde hace tiempo por todos los especialistas del francés hablado en la región parisina. Algunos lingüistas han propuesto incluso llamar a esas "faltas», «francés adelantado», pues su utilización se generaliza en todas las capas de la población a lo largo de las conversaciones familiares ${ }^{3}$. Es el caso de las formas sintácticas o lexicales perseguidas por los puristas de la lengua, pero cuya utilización se extiende: empleo de que en los casos en que se esperaría cuyo, utilización de formas irregulares de los verbos en lugar de las regulares (becho/bacido)etc ${ }^{2}$.

Si el enseñante estima, con toda la razón, que también debe enseñar al niño a utilizar las formas «académicas» de la lengua, es preciso que esté primero persuadido de que el oral no es un lenguaje "sub-escrito" ni las expresiones familiares son «incoherencias" o «perezas». Hacer repetir los diferentes tipos de francés, jugar con las palabras, encontrar la expresión adecuada en cada situación, son ejercicios que todo enseñante puede, a su nivel y teniendo en cuenta la edad de los alumnos, proponer en su clase. Y desde la escuela infantil, el niño podrá apropiarse del lenguaje para alternativamente argumentar, describir, preguntar y ordenar, inventar canciones o aprender poesías.

\section{Notas}

' H. Sinclair, M. Stamback y cols., Les bébés et les choses, PUF 1982.

2 W. Labov, Le Parler ordinaire, Editions de Minuit, 1978.

3 P. Guiraud, Le Français populaire, PUF QSI.

* Traducción de "qui». En francés se utiliza "qui» o "que», como pronombre relativo de persona o cosa, mientras que en castellano "que» sustituye por igual a personas o cosas, siendo mucho menos utilizado el pronombre "quien".

*: Hemos dejado el original, en francés, pues en castellano no existe una correspondencia.

\section{Datos sobre el autor}

Claudine Dannequin es especialista en la enseñanza y uso de la lengua en la escuela primaria. Trabaja actualmente en la Escuela Normal Superior de Fontenay/Saint Cloud, Avenue de la Grille d'Honneur, Le Parc, 92211 Saint Cloud. 